\title{
Implementation and Initial Validation of a 100-kW Class Nested-channel Hall Thruster
}

\author{
Scott J. Hall, ${ }^{*}$ Roland E. Florenz ${ }^{\dagger}$ and Alec D. Gallimore ${ }^{\ddagger}$ \\ University of Michigan, Ann Arbor, MI, 48109, USA \\ Hani Kamhawi ${ }^{\S}$ \\ NASA Glenn Research Center, Cleveland, OH, 44135, USA \\ Daniel L. Brown \\ Air Force Research Laboratory, Edwards AFB, CA, 93523, USA \\ James E. Polk, $\|$ Dan M. Goebel** and Richard R. Hofer ${ }^{\dagger \dagger}$ \\ Jet Propulsion Laboratory, California Institute of Technology, Pasadena, CA, 91109, USA
}

\begin{abstract}
The X3 is a 100-kW class nested-channel Hall thruster developed by the Plasmadynamics and Electric Propulsion Laboratory at the University of Michigan in collaboration with the Air Force Research Laboratory and NASA. The cathode, magnetic circuit, boron nitride channel rings, and anodes all required specific design considerations during thruster development. Thermal modeling was used to properly account for thermal growth in material selection and component design. A number of facility upgrades were required at the University of Michigan to facilitate operation of the X3. These upgrades included a modified propellant feed system, a redesigned power and telemetry breakout box, and numerous updates to thruster handling equipment. The X3 was tested on xenon propellant at two current densities, $37 \%$ and $73 \%$ of the nominal design value. It was operated to a maximum steady-state discharge power of $60.8 \mathrm{~kW}$. The tests presented here served as an initial validation of thruster operation. Thruster behavior was monitored with telemetry, photography and high-speed current probes. The photography showed a uniform plume throughout testing. At constant current density, reductions in necessary mass flow rate of $18 \%$ and $26 \%$ were observed in the three-channel operating configuration as compared to the superposition of each channel running individually. The high-speed current probes showed that the thruster was stable at all operating points and that the channels influence each other when more than one is operating simultaneously. Additionally, the ratio of peak-to-peak AC-coupled discharge current oscillations to mean discharge current did not exceed $51 \%$ for any operating points reported here, and did not exceed $17 \%$ at the higher current density.
\end{abstract}

\section{Nomenclature}

$I_{D} \quad$ discharge current

$\dot{m}_{T} \quad$ total mass flow rate

$P_{D} \quad$ discharge power

$V_{D} \quad$ discharge voltage

${ }^{*}$ Graduate Student, Department of Aerospace Engineering, sjhall@umich.edu, Student Member, AIAA.

$\dagger^{\dagger}$ Graduate Student, Department of Aerospace Engineering, rflorenz@umich.edu, Student Member, AIAA.

¥Arthur F. Thurnau Professor, Department of Aerospace Engineering, alec.gallimore@umich.edu, Fellow, AIAA.

$\S$ Research Engineer, Propulsion and Propellants Branch, hani.kamhawi-1@nasa.gov, Associate Fellow, AIAA.

IProgram Manager, High-Power Electric Propulsion Group, Daniel.Brown@edwards.af.mil, Associate Member, AIAA.

\| Principal Engineer, Propulsion and Materials Engineering Section, james.e.polk@jpl.nasa.gov, Associate Fellow, AIAA.

**Senior Research Scientist, Propulsion and Materials Engineering Section, dan.m.goebel@jpl.nasa.gov, Senior Fellow, AIAA.

${ }^{\dagger \dagger}$ Senior Engineer, Electric Propulsion Group, richard.r.hofer@jpl.nasa.gov, Associate Fellow, AIAA

Distribution A: Approved for public release; distribution unlimited. 1 of 15 


$\begin{array}{ll}v_{\text {axial }} & \text { local axial velocity } \\ \Gamma & \text { local mass flux } \\ \Gamma_{\max , C L} & \text { maximum mass flux along centerline } \\ \hat{\Gamma} & \text { normalized mass flux } \\ \rho & \text { local mass density }\end{array}$

\section{Introduction}

TIGH-power electric propulsion has been identified by NASA and the Air Force as a promising technology 1 to achieve a broad range of near-earth and deep space missions. ${ }^{1,2,3}$ Single-channel Hall-effect Thrusters (HETs) have been demonstrated in ground-based testing to discharge powers of $72 \mathrm{~kW},{ }^{4}$ but mission studies and technology roadmaps put long-term discharge power targets in the range of $300 \mathrm{~kW}$ to $1 \mathrm{MW} .^{5,6,7} \mathrm{Nested-}$ channel Hall-effect thrusters (NHTs) are expected to be capable of high power levels while maintaining a smaller device footprint than comparably-powered single-channel HETs or thruster clusters. In addition, the NHT configuration provides a wider power throttling range than comparable single-channel HETs, having both high-specific impulse and high-thrust operating conditions. ${ }^{8,9}$

In response to this technological need and building on the proof-of-concept work by Liang et al. with the two-channel X2 NHT, ${ }^{10,11}$ the Plasmadynamics and Electric Propulsion Laboratory (PEPL) at the University of Michigan, with the support of the Air Force Research Laboratory (AFRL) and NASA, has developed a 3-channel NHT, designated the X3, ${ }^{12,13,14}$ shown in figure 1.

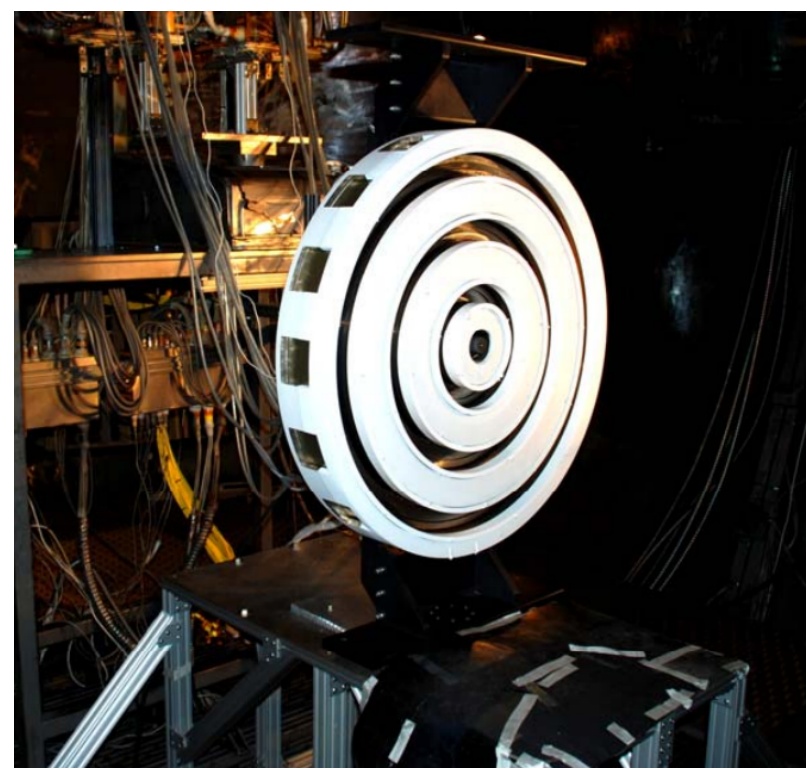

(a) Prior to first firing

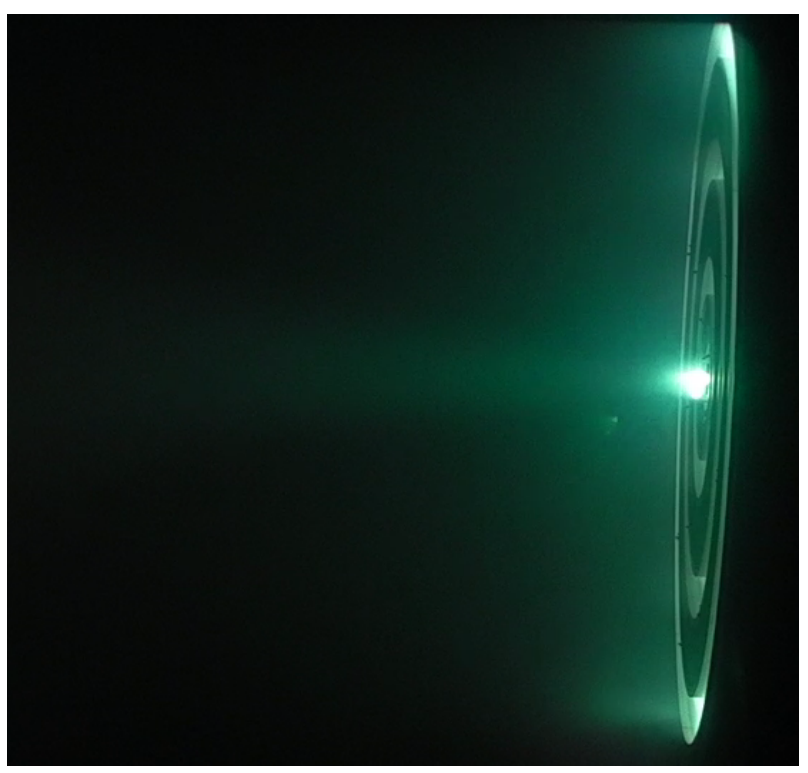

(b) Operational: 3 channels at $60.8 \mathrm{~kW}$ total discharge power, the highest steady-state power level to date

Figure 1. The X3 100-kW class Nested-channel Hall Thruster.

This 100-kW class thruster has an extensive design heritage, building upon development of the 2-channel $\mathrm{X} 2 \mathrm{NHT}$ and the high-power NASA-300M ${ }^{15}-400 \mathrm{M},{ }^{3}-457 \mathrm{mV} 1^{4}$ and $-457 \mathrm{mV} 2^{16}$ single-channel HETs. It has seven distinct operating regimes, consisting of each channel operating individually, all three operating simultaneously, and the various combinations of two. It is designed to operate from discharge voltages of $200 \mathrm{~V}$ to $800 \mathrm{~V}$, allowing for a 200x power throttling range spanning from $1 \mathrm{~kW}$ to $200 \mathrm{~kW}$.

The X3 has been operated previously on krypton. ${ }^{13}$ This paper presents subsequent xenon operation, used as an initial operational validation of the thruster, and additionally presents highlights of the design of the thruster. In Section II, the design considerations of the cathode, magnetic circuit, boron nitride rings, and anode are presented, along with the insights gained from the thermal modeling performed during the design process. In Section III, the various modifications necessary at PEPL to safely handle and operate

Distribution A: Approved for public release; distribution unlimited. 2 of 15 
a thruster the size of the X3 are provided. Section IV outlines the goals and methods used in the testing described herein, and Section V presents the results from the tests. Finally, conclusions and future work are presented in Section VI.

\section{Design Considerations}

\section{A. Cathode}

In preparation for X3 testing, both the NASA Glenn Research Center (GRC) and the Jet Propulsion Laboratory, California Institute of Technology (JPL) built cathodes specifically designed to mount centrally on the X3. Testing to date was completed using the cathode designed by the JPL. This cathode, described in Ref. 17, was a lanthanum hexaboride $\left(\mathrm{LaB}_{6}\right)$ hollow cathode that has been tested (separate from the X3) at discharge currents ranging from 10 to $300 \mathrm{~A}$ at discharge voltages of 14 to $30 \mathrm{~V}$, depending on current and gas flow rate. Its design was based on those of previous $\mathrm{LaB}_{6}$ hollow cathodes designed by the JPL for the 6 kW H6 Hall thruster, which are capable of 10 to 100 A of discharge current. ${ }^{18}$ The X3 cathode from the JPL featured a molybdenum cathode tube, a tungsten cathode orifice plate, a graphite keeper, and a tantalum sheathed heater of similar construction to those used in the $\mathrm{H} 6$ cathodes. The cathode required $380 \mathrm{~W}$ of heater power to heat and ignite. Additionally, external gas injectors ${ }^{19}$ were used to reduce the generation of energetic ions in the cathode plume. Figure 2 shows the fully assembled cathode from the JPL. ${ }^{17}$

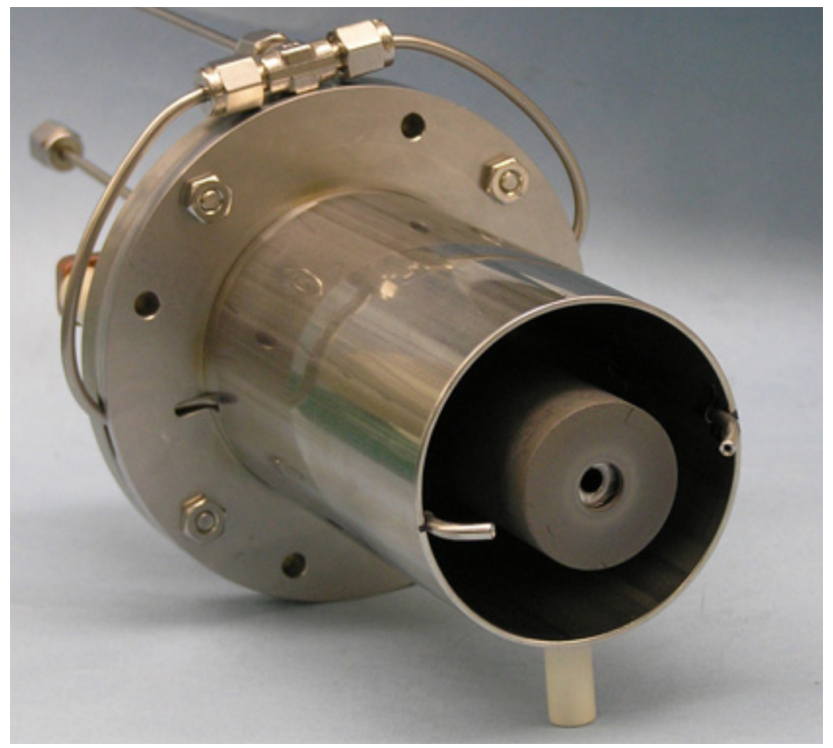

Figure 2. The JPL-developed $\mathrm{LaB}_{6}$ cathode assembly, complete with the cathode plume external gas injectors. Reproduced from figure 4 in Ref. 17.

Future tests will also utilize the cathode designed by GRC. This hollow cathode is based on the work described in Refs. 20 and 21 and features a novel BaO-impregnated tungsten emitter designed to attain lower peak emitter temperatures than typical state-of-the-art designs.

\section{B. Magnetic Circuit}

The magnetic circuit of the X3 was designed to support three simultaneously-operating concentrically-nested discharge channels. Using the same techniques developed for the X2, ${ }^{10}$ the circuit supports three simultaneous magnetic lens topologies; magnetic field directions flip between channels to maintain quasi-radial fields within the channels and to minimize magnetic circuit hardware. That is, the middle channel field points radially in the opposite direction of that of the inner and outer channels. The design work used a commercially-available electromagnetic field simulation software.

Using linear and rotary motion stages and a magnetic field probe, the magnetic field of the X3 was verified prior to initial thruster operation. The goals of this test were to ensure that radial profiles matched simulation, to ensure azimuthal uniformity, and to ensure that the field achieved the desired strength. It

Distribution A: Approved for public release; distribution unlimited. 
was found that the azimuthal standard deviation did not exceed $4.3 \%$ for any channel and the magnetic field strength met or slightly exceeded the design value for all three channels.

\section{Boron Nitride Channel Wall Lining}

Boron nitride (BN) is often used in Hall thrusters to partially ${ }^{22}$ or fully ${ }^{3,10,15,23}$ line the discharge channel walls to electrically isolate them. The X3 features BN rings lining a portion of the discharge channel walls near the exit plane. The size of the X3 is such that monolithic rings were unfeasible, especially for the middle and outer channels, due to the lack of availability of $\mathrm{BN}$ in necessary sizes. As such, the BN channel rings of the X3 were designed using insight from the NASA-457Mv1. ${ }^{22}$ The rings were separated into multiple arc segments that were held in place by a retainer spring and the front magnet poles. Fiberglass rope was used as a gasket between each segment to provide isolation during thermal expansion.

\section{Anodes}

Typically, Hall thruster anodes serve the additional purpose of neutral propellant distributors, and as such are one of the critical components of these devices. The anode design considerations discussed herein concern this neutral propellant distribution. Neutral flow dynamics have been shown to affect thruster performance, stability, and lifetime. ${ }^{24}$ The primary metric used to evaluate the anode designs was thus the neutral flow uniformity, analyzed in both the radial and azimuthal directions. This uniformity was evaluated using normalized mass flux:

$$
\begin{gathered}
\Gamma=\rho \cdot v_{\text {axial }} \\
\hat{\Gamma}=\frac{\Gamma}{\Gamma_{\max , C L}}
\end{gathered}
$$

where $\Gamma$ is the local mass flux, $\rho$ is the local mass density, $v_{\text {axial }}$ is the local axial velocity, $\hat{\Gamma}$ is the normalized mass flux, and $\Gamma_{\max , C L}$ is the maximum mass flux along channel centerline. Based on the work of Reid, ${ }^{24}$ analysis of flow uniformity of various anode designs was completed using a commercially-available computational fluid dynamics (CFD) software package.

Three major design concepts for the X3 anode were investigated: porous, drop-in, and integrated. Notional cross sections of each are given in figure 3.

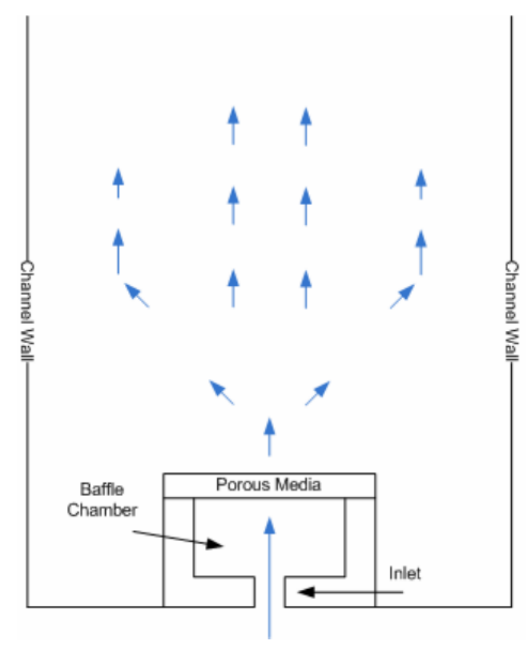

(a) Porous anode.

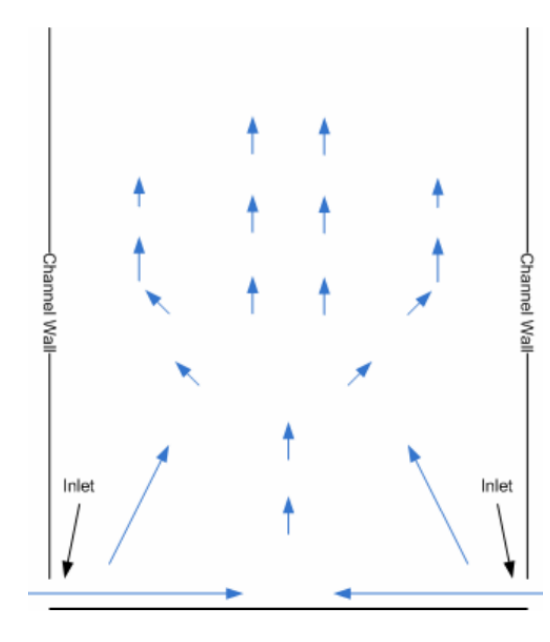

(b) Integrated anode.

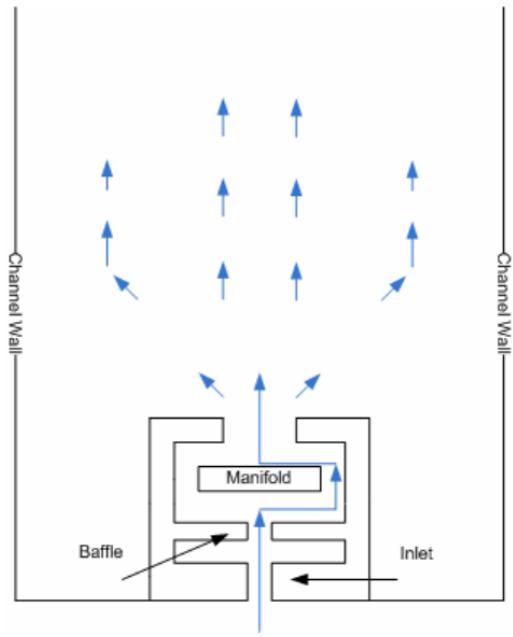

(c) Drop-in anode.

Figure 3. Notional cross-sections of the three anode designs considered for the X3.

The porous design used a porous material placed over a propellant reservoir such that a uniform flow could be developed without requiring complex machining. The integrated design merged the gas distribution into the discharge channel walls in an attempt to reduce part count. The drop-in design used a series of

Distribution A: Approved for public release; distribution unlimited.

$$
4 \text { of } 15
$$


baffles and manifold holes to evenly distribute the propellant throughout the channel. Modeling of all three design types was completed in the CFD software, and to reduce computational expense, only the outer channel was modeled. The outer channel was chosen because it was the most extreme in size and expected flow range.

A drop-in anode was ultimately selected for the X3. The porous design was rejected due to a lack of porous material available in necessary sizes, and manufacturing complexity issues eliminated the integrated design.

Once a drop-in anode design was selected, design iterations were simulated in the CFD software for all three channels. Due to the expansive throttling range of the X3, the anodes were designed over flow rates ranging from $20 \%$ to $180 \%$ of the nominal flow rate. The simulation results for the final anode designs indicate they are capable of producing both radially and azimuthally uniform flow fields. ${ }^{12}$

Prior to final thruster assembly, the uniformity of the flow fields was experimentally verified in an acceptance test modeled after the Anode Pressure Acceptance Test of Reid. ${ }^{24}$ Cold neutral gas was flowed through each anode, and a pressure transducer attached to a pitot tube measured the pressure distribution across the anodes using linear and rotary motion stages. Mock channel walls were created from sheet aluminum to more accurately replicate the thruster structure. The primary goals of this test were to verify pressure profile shape radially across each channel and to ensure that azimuthally-uniform flow was being produced. Azimuthal deviation, measured 0.29 of the channel length upstream of the exit plane of each channel, was found to be $5 \%$ for the inner channel and $13 \%$ for both the middle and outer channel; gauge error was \pm $10 \%$. This error was deemed acceptable, as were the pressure profiles.

\section{E. Thermal Modeling}

A thermal modeling effort was undertaken during the design process of the X3 due to the thruster's unprecedented size and power level. The thruster was simulated at power levels between $70 \mathrm{~kW}$ and 200 $\mathrm{kW}$ to bracket the operating regime outside typical HET operation to date. The simulations were fully three-dimensional.

Material selection for various thruster components were based on the modeling results. It was imperative that materials not lose strength or melt even at the upper end of thruster operation. It was a concern during thruster design that, due to their size and expected thermal loads, thermal growth for many components could potentially approach values equal to or greater than machining tolerances. The modeling effort allowed thermal expansion to be properly incorporated into component design.

\section{Facility Modifications}

Substantial infrastructure upgrades were necessary at PEPL to accommodate the handling and operation of a thruster the size, mass, and power of the X3. These included upgrades to the propellant feed system, power supplies, and electrical infrastructure, along with a completely new system for thruster handling and installation in the vacuum chamber.

\section{A. Test Facilities Overview}

The testing described herein was performed in the Large Vacuum Test Facility (LVTF) at PEPL. The LVTF is a $200 \mathrm{~m}^{3}, 9 \mathrm{~m}$ long, $6 \mathrm{~m}$ diameter, stainless-steel-clad vacuum chamber. Rough vacuum is achieved using two 2000 CFM blowers backed by four 400 CFM mechanical roughing pumps. The ultimate chamber base pressure, in the low $10^{-7}$ Torr, is achieved with seven CVI-TM1200 internal cryopumps with liquid-nitrogencooled shrouds that provide a nominal pumping speed of 500,000 l/s on air and 240,000 l/s on xenon. During operation, chamber pressure was measured by a Bayard-Alpert ionization gauge mounted at the top of the chamber, axially co-located with the thruster exit plane. The gauge was connected to a gauge controller and had an uncertainty of $\pm 20 \% .{ }^{25}$

\section{B. Beam Dump Extension}

Early X3 operation made clear that the end cap of the LVTF needed to be protected from plume exposure in its entirety. During this period of testing, there were noticeable differences between surfaces exposed to the plasma and those where the plasma had no line-of-sight (e.g., those behind struts or other structures,

Distribution A: Approved for public release; distribution unlimited.

$$
5 \text { of } 15
$$

American Institute of Aeronautics and Astronautics 
or behind the existing graphite plume target or "beam dump"). Instead of being a dull black and coated in carbon deposits, as is usually the case for the endcap and other chamber surfaces after operation of lowerpower thrusters, the exposed portions of the endcap appeared bright and shiny after the first X3 tests. It is suspected that the beam was so wide at the endcap that it was plasma-polishing the stainless steel cladding, cleaning it of any carbon deposits. This raised the concern of doing serious long-term damage to the LVTF. To alleviate this concern while maintaining setup flexibility, a removable system was designed that increased the beam dump surface area by a factor of approximately 2.5 .

\section{Propellant Feed System}

A new propellant feed system for the LVTF was designed that collected existing low-flow mass flow controllers (MFCs) and integrated them in parallel with the new high-flow (several 100s of sccm) MFCs necessary for X3 operation. The system had four stainless steel feed lines into the LVTF, with each line having the choice of a low- or high-flow controller. Calibration was achieved using one of two specialized calibration units included in the new system; for each controller, multiple calibration points were taken and a linear fit was used to determine the flow for any arbitrary set point.

\section{Power Supplies}

All three channels of the X3 required high-voltage, high-current power supplies to provide discharge power to the anodes. To ensure capability to run all three channels simultaneously from separate supplies, a $60-\mathrm{kW}$ (1000 V/60 A maximum) supply, a 100-kW (1000 V/100 A maximum) supply, and a 150-kW (1000 V/150 A maximum) supply were acquired and installed.

\section{E. Power and Telemetry Breakout Box}

The power and telemetry breakout box designed for X3 operation was based heavily on a similar box built by Dr. Raymond Liang for the X2 operation ${ }^{10}$ with expanded capability for the X3. The breakout box serves as the way-point between the thruster inside the vacuum chamber and the external power supplies. Additionally, it houses the circuitry necessary for thruster telemetry. Table 1 provides a summary of the various measurement methods and the telemetry items measured with each.

\begin{tabular}{ll} 
Measurement Method & Telemetry Items \\
\hline \hline Voltage dividers & $\begin{array}{l}\text { discharge voltage, keeper voltage, } \\
\text { cathode-to-ground voltage }\end{array}$ \\
\hline Current shunts & magnet, heater, and keeper current \\
\hline Magneto-resistive sensors & discharge current \\
\hline Direct measurement & magnet voltage, heater voltage
\end{tabular}

Table 1. The various measurement methods employed in the breakout box, and the telemetry items measured with each.

\section{F. Thruster Handling}

Handling a thruster the size and mass of the X3 in a safe and efficient manner in a laboratory setting was a non-trivial task. As such, new techniques and equipment were necessary for assembly, storage, transport, and installation of the thruster.

\section{Assembly Rig}

A standard-configuration holding fixture was chosen as a stand-alone thruster assembly and storage device. This rig served three purposes: it allowed a safe means to assemble the thruster "laying down" (i.e. exit plane horizontal and facing upward) and then rotate to the "upright" position (i.e. exit plane vertical); it served as a long-term storage apparatus for the thruster; finally, as it was on wheels, it allowed for easy

Distribution A: Approved for public release; distribution unlimited.

$$
6 \text { of } 15
$$

American Institute of Aeronautics and Astronautics 
maneuvering of the thruster around the laboratory prior to installation inside the LVTF. A picture of the fixture prior to thruster assembly is shown in figure 4 .

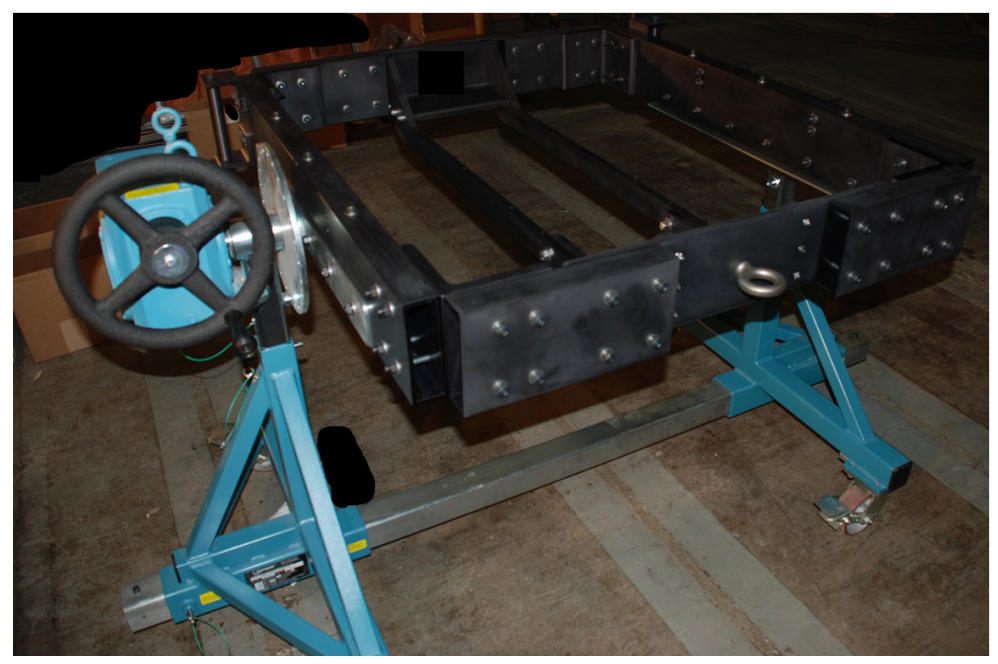

Figure 4. The holding fixture used for assembling and housing the X3.

\section{Gantry Crane}

A means to move the thruster from floor level to the mounting height inside the LVTF (approximately 2 meters above the floor) was also necessary. A gantry crane was chosen for this purpose. This crane safely supported the thruster weight, was tall enough to reach the height of the thrust stand, and had a wheelbase wide enough to clear the width of the mounting table. It was equipped with a manual chain hoist and was mounted on v-groove casters.

\section{Nitrogen Purge Box}

A nitrogen purge facility was necessary to keep the thruster in a stable, dry environment while not being operated. A modular aluminum nitrogen purge box was affixed directly to the assembly rig and thruster frame. A nitrogen tank was plumbed directly to the thruster anodes to provide a constant stream of dry nitrogen.

\section{Initial Validation}

First firing of the X3 was performed with krypton propellant and was described in detail in Ref. 13. Once the thruster was burned in at $300 \mathrm{~V}$ discharge voltage (which used krypton propellant and is described below), testing continued with xenon propellant. The xenon testing, which served as an initial operational validation of the thruster, is described herein. For this initial validation of the X3, a test matrix was chosen such that a comparison could be made across the seven different operational modes of the thruster, between the two propellants, and across two current densities.

The operating conditions presented here are divided into two sets in the same fashion that X2 operating conditions were separated into triads. ${ }^{26}$ An X3 operational set consists of seven distinct operating conditions representing the seven operational configurations of the thruster (each channel operating alone, all three operating simultaneously, and the various combinations of two). Sets are identified by the total nominal discharge current seen in the three-channel configuration (100 A and $200 \mathrm{~A}$ here). The discharge current density was held constant within a set and was controlled via the propellant mass flow rate. The magnetic field shape for each channel was kept constant, though the magnitude of the field varied. The coils for each channel were only activated when that channel was operational.

Both sets presented here were at $300 \mathrm{~V}$ discharge voltage. The $100 \mathrm{~A}$ set achieves approximately $37 \%$ of thruster nominal current density and the $200 \mathrm{~A}$ set achieves approximately $73 \%$ of the same. It should be noted that the $200 \mathrm{~A}$ set was tested after the $100 \mathrm{~A}$ set, meaning the thruster accumulated approximately

Distribution A: Approved for public release; distribution unlimited. 7 of 15 
30 hours of additional run time between sets. Whether certain behavioral differences between sets discussed here are due to the difference in current density or additional thruster run time is unclear, but regardless of source, the 200 A set is considered closer to future expected thruster behavior due to these factors.

\section{A. Burn in}

When run at a particular discharge voltage for the first time, each channel of the X3 was allowed to burn in before any measurements were taken. Each channel of the thruster was run separately at the new discharge voltage for approximately 4 hours. During this period, both mean discharge current and ACcoupled discharge current oscillations were higher than subsequent steady-state operation. This process will be used in future testing until the thruster has been run through its full operating envelope.

This burn in is to be distinguished from a bake out in that burn in occurred once per channel for each discharge voltage, whereas a bake out is used to remove any accumulated moisture from the thruster every time it is exposed to atmosphere.

\section{B. Experimental Setup}

Throughout the entire test campaign, analysis was limited to three main diagnostics: thruster telemetry, photographs, and high-speed current probes. The thruster telemetry was obtained using the power and telemetry breakout box and a series of thermocouples, each running to a data logger switch. Propellant flow rate was recorded separately using the software used to operate the mass flow controllers. This information was used to monitor thruster performance, stability, temperature, and propellant flow rates in real time during testing.

Photographs were used to provide a qualitative understanding of the plasma structure and thruster stability. Two DSLR cameras and an HD video camera were used. One DSLR pointed toward the thruster face approximately $20^{\circ}$ from thruster centerline, the other provided a side view of the thruster, and the HD video camera was positioned to provide a view between the two.

High-speed current probes were used to measure the AC component of each channel's discharge current. A split-core Hall current sensor attached to a current probe amplifier was employed on each discharge current line outside the vacuum chamber. All three sensors were connected to the same digital oscilloscope.

\section{Results and Discussion}

\section{A. Telemetry}

The thruster telemetry for each test condition is presented in the Appendix in table 2. As the ionization gauge is calibrated for $\mathrm{N}_{2}$, the pressures in the table have been corrected for xenon.

As more channels are turned on, the total mass flow rate drops below the superposition value of the individual channel flow rates. When running all three channels (test conditions Xe7 and Xe14), the total mass flow rates are respectively $74 \%$ and $82 \%$ of the summed single channel values for each condition (Xe1-Xe3 and $\mathrm{Xe} 8$-Xe10, respectively), as illustrated in figure 5. This is the same propellant cross-utilization phenomenon seen previously in the krypton tests. ${ }^{13}$ Further exploration and characterization of this significant savings in propellant is a point of particular interest for future work.

\section{B. Photographs}

Example photographs of the type taken throughout this testing campaign are given for the $200 \mathrm{~A}$ set in figure 6. Throughout, the images suggested uniform discharges; no hot spots ${ }^{\mathrm{a}}$ were identified from any camera angle. The photographs also yielded an interesting phenomenon requiring future evaluation: that of the "saber-shaped" plume seen in operating conditions Xe11 and Xe12. This shape presented itself in some form on both propellants at all test conditions run to date in which the inner and middle or middle and outer channels were run simultaneously. The structure is similar to one found in the X2 under certain magnetic field conditions.

\footnotetext{
${ }^{a}$ Hot spots are defined as locations on the channel walls or the anode itself that are substantially brighter than the rest of the channel
}

Distribution A: Approved for public release; distribution unlimited. 8 of 15

American Institute of Aeronautics and Astronautics 


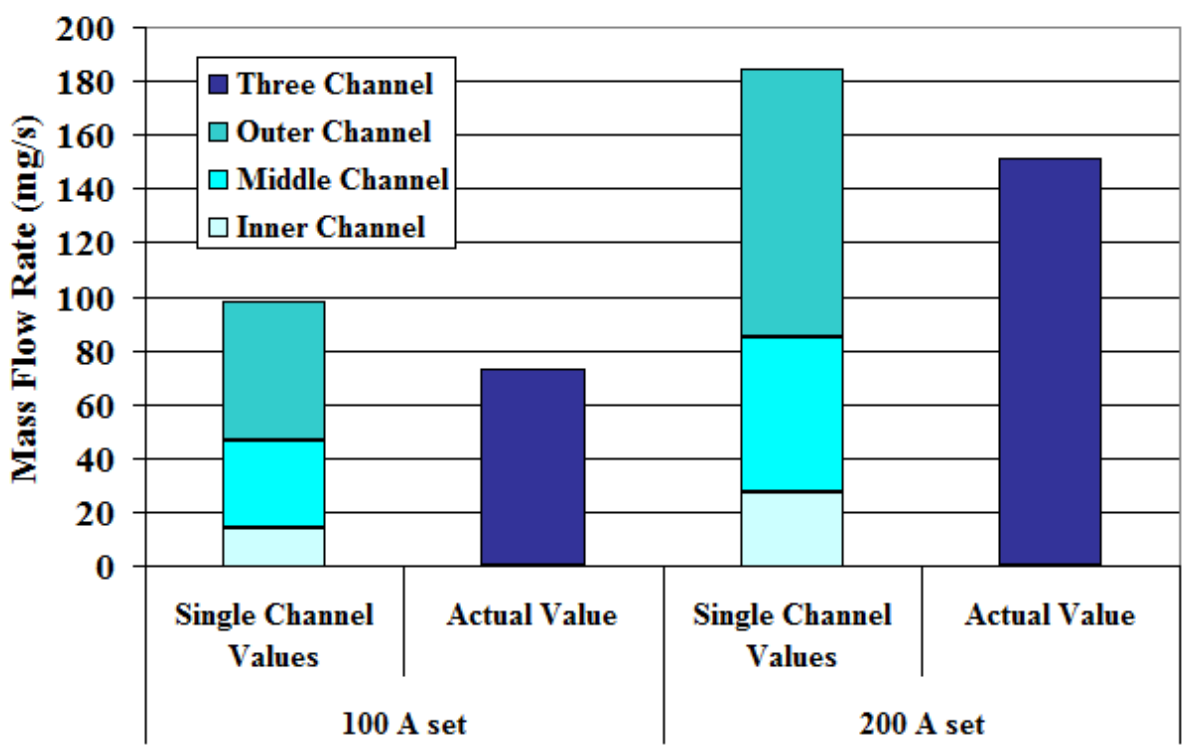

Figure 5. The propellant cross-utilization phenomenon. For each set, the single-channel propellant flow rates are stacked on the left, and the actual total propellant flow rate is on the right.

\section{High-Speed Current Probes}

The ratio of peak-to-peak AC current oscillations to mean discharge current provides insight into thruster stability. It is generally understood that lower values of this ratio are correlated with more stable thruster operation. ${ }^{26}$ Figure 7 presents this ratio for all 14 xenon test conditions considered here.

The thruster got significantly "quieter" running at the 200 A set. Noting the above uncertainties about the cause of this change, it is expected that this trend will continue as the current density approaches the nominal value. Potentially more important than that is that all values of the peak/mean ratio reported are significantly smaller than what is considered typical for other thrusters, though it should be noted that the strength (though not the shape) of the magnetic field was used to coarsely minimize the peak-to-peak oscillation value. The BPT-4000 saw a peak/mean ratio of $95 \%$ at its nominal $300 \mathrm{~V} / 15 \mathrm{~A}$ condition during ground testing at JPL, ${ }^{27}$ and typical values for the X2 ranged from $75 \%$ to $140 \%{ }^{26}$ None of the peak-topeak values for the X3 reported here exceeded $51 \%$ of the mean discharge current, and in the $200 \mathrm{~A}$ set none exceeded $17 \%$. The reasons for this significant drop from other thrusters are unknown, but the smaller oscillations are seen as positive.

In addition to the raw high-speed current data, power spectral densities (PSDs) of the AC-coupled discharge current traces were created using the data from the high-speed current probes and the built-in PSD functionality in MATLAB. PSDs for the $100 \mathrm{~A}$ set are presented in figure 8 and for the $200 \mathrm{~A}$ set in figure 9 .

These PSDs are a tool to provide insight into channel behavior and interaction. Much of the same behavior seen in the krypton tests ${ }^{13}$ was seen here with xenon propellant, and the overall characteristics of the PSDs are similar. With some notable exceptions, the PSDs display strong breathing mode oscillations on the order of $10 \mathrm{kHz}$. This breathing mode varies in frequency across channels depending on thruster power level and channel configuration. It essentially disappears for the inner channel when the inner channel is operating in dual-channel modes with either other channel, but then reappears in three-channel operation. Generally, when comparing the $100 \mathrm{~A}$ set to the $200 \mathrm{~A}$ set, it is seen that the breathing mode frequencies of similar operating conditions shifted higher for the higher-current case.

The difference between single-channel operation and three-channel operation can be seen in both figures. In both sets, the peaks of all three channels are shifted up in frequency when moving from single-channel to three-channel operation. In the $100 \mathrm{~A}$ set, the peaks do not fully synchronize across the three channels in Xe7, but in the $200 \mathrm{~A}$ set, the peaks in Xe14 are fully synchronized at $14.7 \mathrm{kHz}$. This behavior was seen in similar tests of the X2, ${ }^{26,28}$ and is referred to by Liang et al. as "full coupling", in which multiple

Distribution A: Approved for public release; distribution unlimited.

$$
9 \text { of } 15
$$




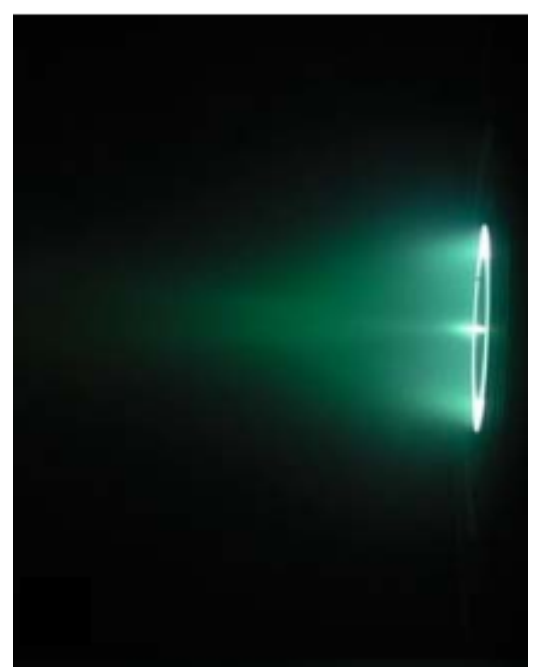

(a) Xe8: inner channel

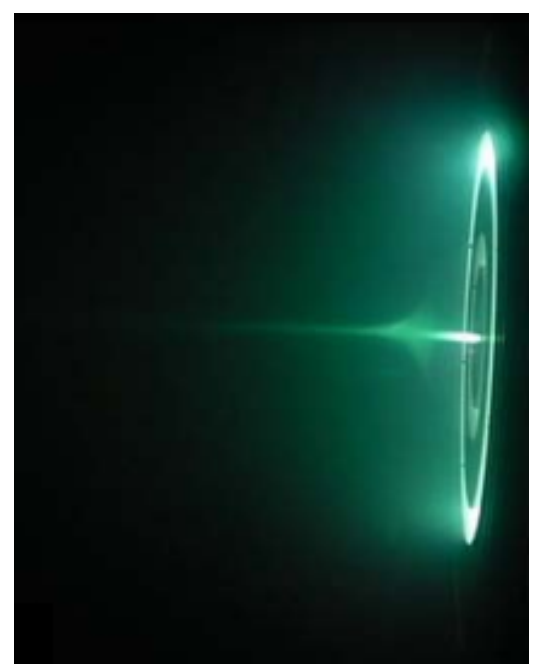

(d) Xe11: inner and middle channels

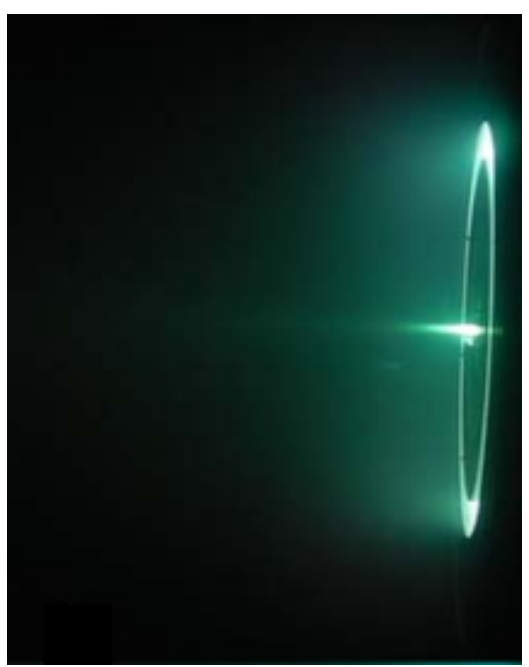

(b) Xe9: middle channel

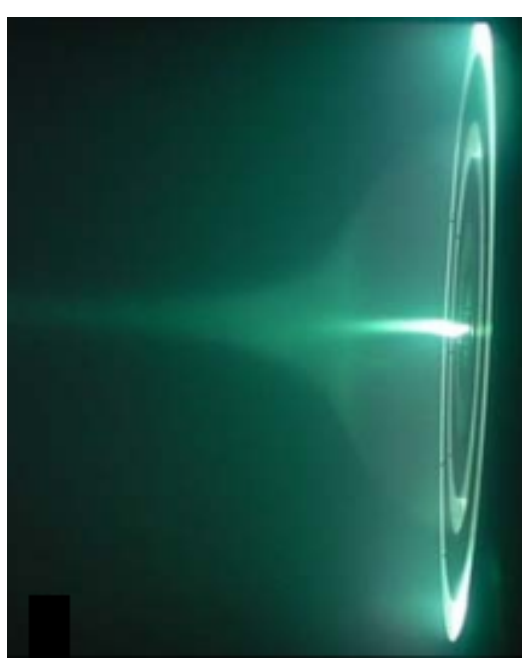

(e) Xe12: middle and outer channels

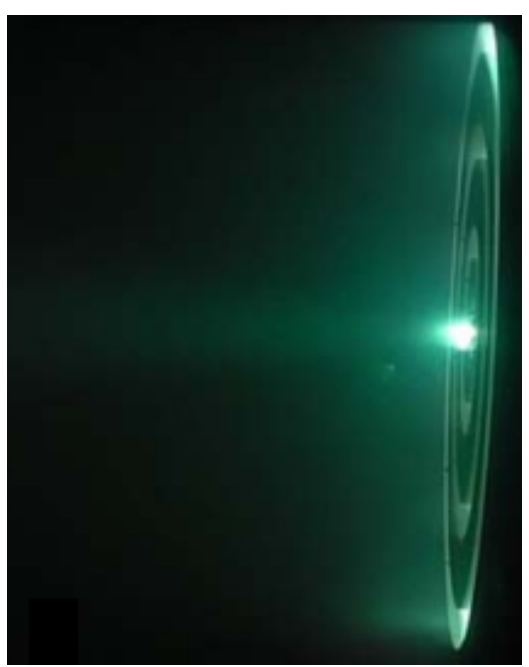

(g) Xe14: inner, middle, and outer channels

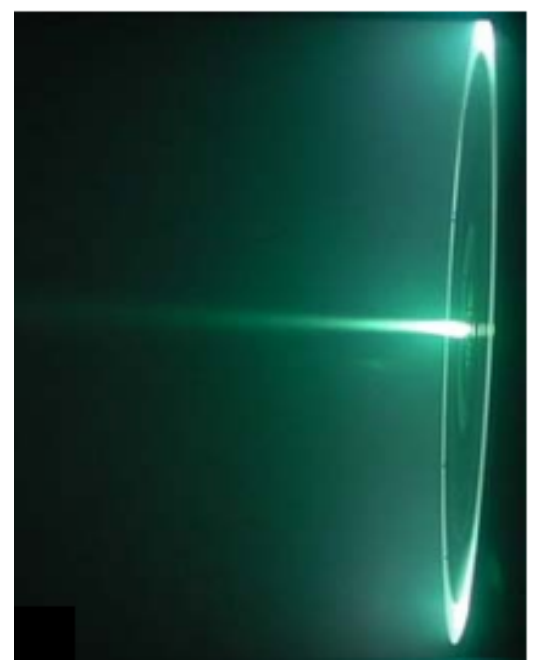

(c) Xe10: outer channel

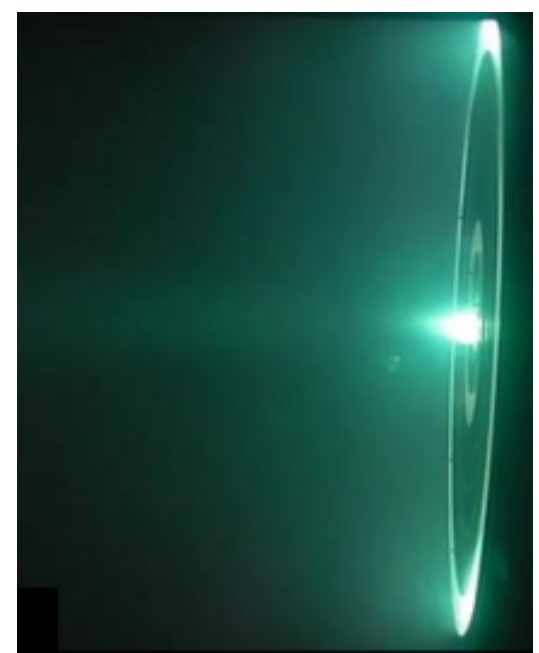

(f) Xe13: inner and outer channels

Figure 6. All seven operating modes of the X3 in the 200 A set of operating conditions. All photographs were taken with the HD video camera with the same camera settings.

Distribution A: Approved for public release; distribution unlimited.

$$
10 \text { of } 15
$$




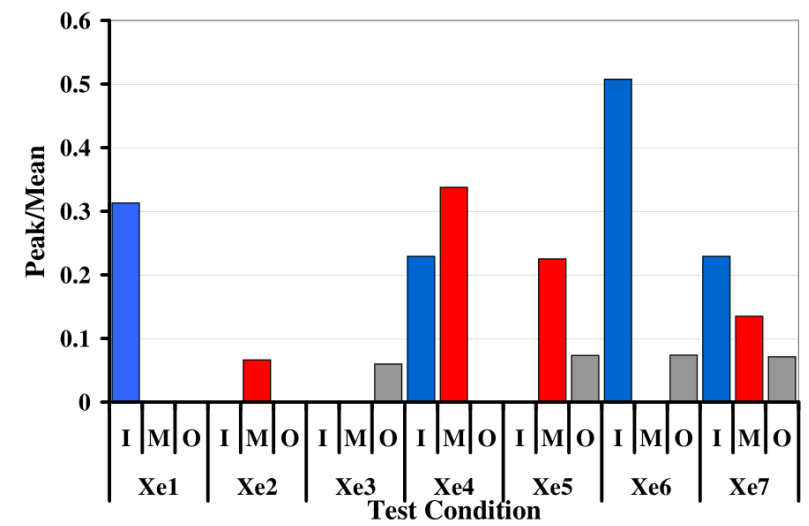

(a) $100 \mathrm{~A}$ set

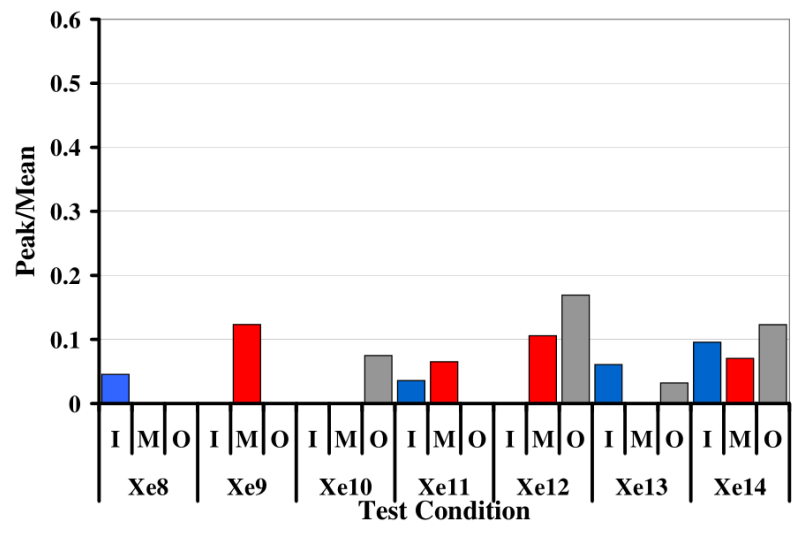

(b) 200 A set

Figure 7. The ratio of peak-to-peak AC current oscillation to mean discharge current for both sets of X3 operating conditions.

discharge channels exhibit nearly identical frequency spectra when operating simultaneously. McDonald et al. suggest this behavior indicates pure joint oscillation between the channels at a single main breathing mode frequency, ${ }^{26}$ though whether the channels of the X3 are oscillating together in time or simply at the same frequency has not been verified. Why the $200 \mathrm{~A}$ set three-channel case exhibits full coupling while that of the $100 \mathrm{~A}$ set does not is unclear, but again, the $200 \mathrm{~A}$ set is taken to be more indicative of expected future X3 behavior. Full coupling appears again in the 200 A set in Xe12, in which case the two spectra share similar shape and peak locations, except for the secondary peak in the outer channel. The source of this low-frequency second peak is unknown.

One anomaly in this data is in operating condition Xe13 in figure 9. A large, broad spike around $73 \mathrm{kHz}$ is seen in both channels. The work of Jorns and Hofer ${ }^{29}$ suggests this is a cathode oscillation, but its exact source and the reason it appeared in Xe13 but not in Xe6 is unknown.

Distribution A: Approved for public release; distribution unlimited. 11 of 15 


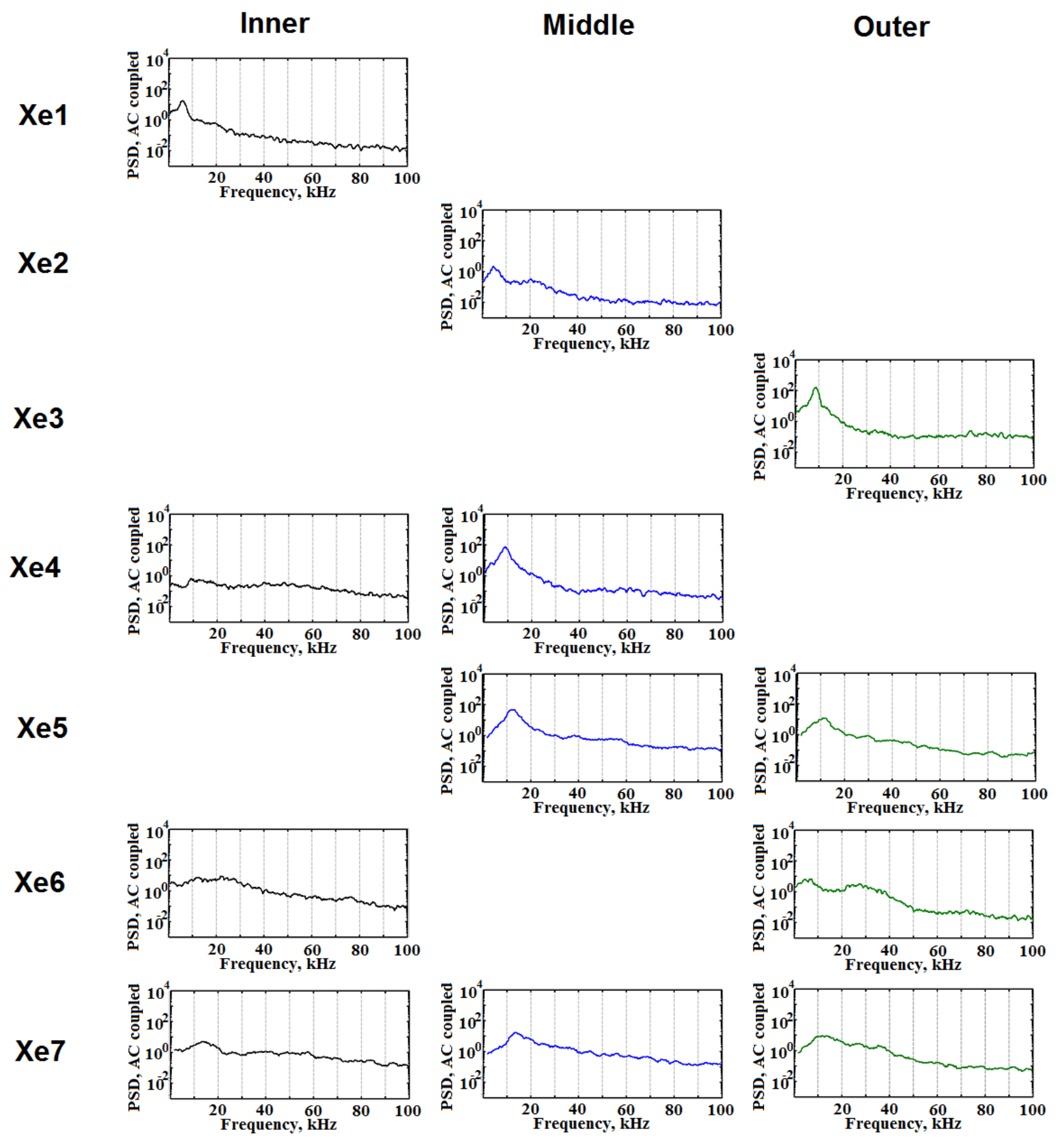

Figure 8. The AC-coupled power spectral densities of the discharge currents for the $300 \mathrm{~V} / 100 \mathrm{~A}$ set (Xe1-Xe7)

Distribution A: Approved for public release; distribution unlimited.

$$
12 \text { of } 15
$$




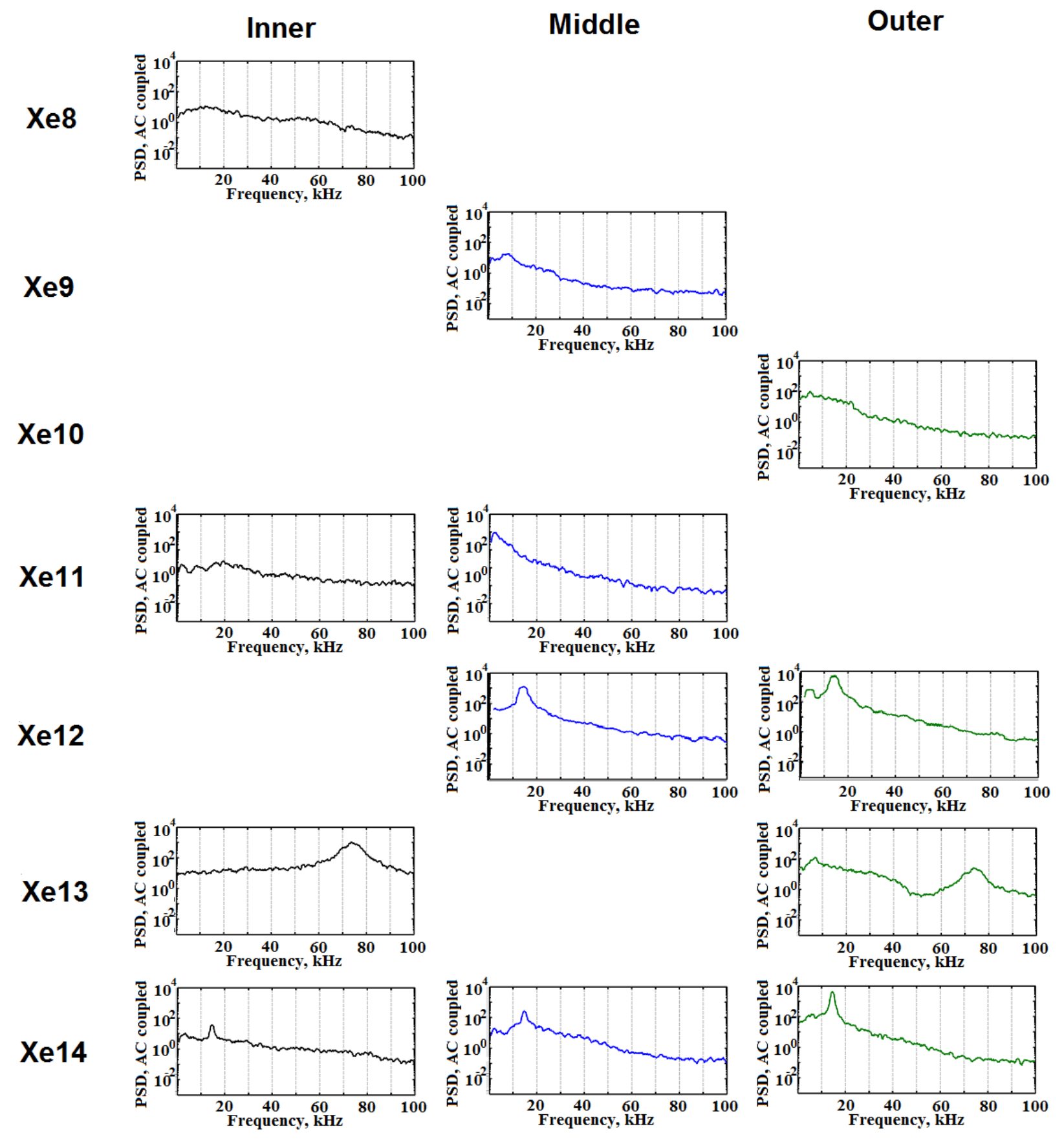

Figure 9. The AC-coupled power spectral densities of the discharge currents for the $300 \mathrm{~V} / 200$ A set (Xe8Xe14)

Distribution A: Approved for public release; distribution unlimited.

$$
13 \text { of } 15
$$




\section{Conclusions and Future Work}

The X3 has operated as expected on xenon. It has been operated up to $73 \%$ of nominal current density and a total discharge power of $60.8 \mathrm{~kW}$, with positive behavioral trends as current density increased. The channels have been shown to affect each other when operating simultaneously, and by some mechanism to share propellant. At the higher current density, this sharing results in propellant savings of $18 \%$ in the three-channel configuration when compared to the summation of individual channel values.

This work served as a very preliminary exploration of the operation of the X3. Initial validation of the same type detailed here will continue throughout the remainder of the thruster operating envelope. From there, a full performance characterization of the thruster is planned, including time-averaged diagnostics in both the near- and far-field plume and thrust measurements. In addition, there is strong interest in better characterizing channel interaction during multi-channel operation, including both the propellant crossutilization and full-coupling phenomena. The effect of changes in magnetic field shape will also be studied. These next steps will better characterize what has proven to be a stable thruster, capable of high discharge power and performing as designed.

\section{Appendix}

\begin{tabular}{ccccccc} 
Test Condition & Channel(s) & $\mathrm{V}_{D}[\mathrm{~V}]$ & $\mathrm{I}_{D}[\mathrm{~A}]$ & $\mathrm{P}_{D}[\mathrm{~kW}]$ & $\dot{m}_{T}[\mathrm{mg} / \mathrm{s}]$ & Pressure [Torr-Xe] \\
\hline \hline \multicolumn{7}{c}{$100 \mathrm{~A}$ SET } \\
Xe1 & $\mathrm{I}$ & 299.2 & 13.1 & 3.9 & 14.0 & $7.2 \times 10^{-6}$ \\
Xe2 & $\mathrm{M}$ & 299.1 & 31.7 & 9.5 & 32.3 & $1.6 \times 10^{-5}$ \\
Xe3 & $\mathrm{O}$ & 299.2 & 55.2 & 16.5 & 52.1 & $2.7 \times 10^{-5}$ \\
Xe4 & $\mathrm{I}+\mathrm{M}$ & 299.6 & 45.1 & 13.6 & 38.0 & $2.1 \times 10^{-5}$ \\
Xe5 & $\mathrm{M}+\mathrm{O}$ & 298.1 & 86.9 & 25.9 & 68.2 & $3.5 \times 10^{-5}$ \\
Xe6 & $\mathrm{I}+\mathrm{O}$ & 299.5 & 68.9 & 20.6 & 58.1 & $3.1 \times 10^{-5}$ \\
Xe7 & $\mathrm{I}+\mathrm{M}+\mathrm{O}$ & 299.2 & 100.3 & 30.1 & 73.3 & $3.5 \times 10^{-5}$ \\
\hline \multicolumn{7}{c}{$200 \mathrm{~A}$ SET } \\
\hline \hline Xe8 & $\mathrm{I}$ & 299.2 & 28.6 & 8.6 & 27.2 & $1.5 \times 10^{-5}$ \\
Xe9 & $\mathrm{M}$ & 294.3 & 69.7 & 20.5 & 57.4 & $2.9 \times 10^{-5}$ \\
Xe10 & $\mathrm{O}$ & 301.0 & 110.8 & 33.3 & 100.0 & $4.6 \times 10^{-5}$ \\
Xe11 & $\mathrm{I}+\mathrm{M}$ & 296.0 & 98.6 & 29.1 & 70.0 & $3.5 \times 10^{-5}$ \\
Xe12 & $\mathrm{M}+\mathrm{O}$ & 298.2 & 184.5 & 54.9 & 133.1 & $6.0 \times 10^{-5}$ \\
Xe13 & $\mathrm{I}+\mathrm{O}$ & 299.5 & 140.0 & 42.0 & 114.3 & $5.3 \times 10^{-5}$ \\
Xe14 & $\mathrm{I}+\mathrm{M}+\mathrm{O}$ & 296.9 & 204.5 & 60.8 & 151.6 & $6.7 \times 10^{-5}$
\end{tabular}

Table 2. Telemetry for both sets of xenon operating conditions.

\section{Acknowledgments}

The authors would like to thank the following individuals and organizations for their support and contributions: Dr. Mitat Birkan of the Air Force Office of Scientific Research, Dr. James Haas of AFRL, Dr. Peter Peterson of the Aerojet-Rocketdyne Corporation (at the time of his contribution, of ElectroDynamic Applications, Inc), Dr. Thomas Liu of the Georgia Institute of Technology (at the time of his contribution, of the University of Michigan), Mr. Kevin Blake of NASA GRC, and Mr. Joseph Blakely of AFRL. Without their help and support this work would not have been possible. Roland Florenz was funded by the Michigan/AFRL Center for Excellence in Electric Propulsion and the Michigan Space Grant Consortium. Scott Hall is supported by the National Science Foundation Graduate Research Fellowship Program under Grant No. DGE 1256260.

Distribution A: Approved for public release; distribution unlimited. 14 of 15 


\section{References}

${ }^{1}$ Jacobson, D. and Jankovsky, R., "Performance Evaluation of a $50 \mathrm{~kW}$ Hall Thruster," 35th Joint Propulsion Conference, American Institute of Aeronautics and Astronautics, Los Angeles, CA, 1999.

${ }^{2}$ Jankovsky, R., Tverdokhlebov, S., and Manzella, D., "High Power Hall Thrusters," 35th Joint Propulsion Conference, AIAA, Los Angeles, CA, 1999.

${ }^{3}$ Jacobson, D., Hofer, R., and Peterson, P., "NASA's 2004 Hall Thruster Program," 40th Joint Propulsion Conference, American Institute of Aeronautics and Astronautics, Ft. Lauderdale, FL, 2004.

${ }^{4}$ Manzella, D., Jankovsky, R., and Hofer, R., "Laboratory Model 50 kW Hall Thruster," 38th Joint Propulsion Conference, National Aeronautics and Space Administration, Glenn Research Center, Indianapolis, IN, July 2002.

${ }^{5}$ Brophy, J. R., Gershman, R., Strange, N., Landau, D., Merrill, R., and Kerslake, T., "300-kW Solar Electric Propulsion System Configuration for Human Exploration of Near-Earth Asteroids," 47th Joint Propulsion Conference, Vol. 5514, AIAA, San Diego, CA, Aug. 2011.

${ }^{6}$ Casaregola, C., Cesaretti, G., and Andrenucci, M., "HiPER: A Roadmap for Future Space Exploration with Innovative Electric Propulsion Technologies," 31st International Electric Propulsion Conference, Ann Arbor, MI, 2009.

${ }^{7}$ Meyer, M., Palaszewski, B., Goebel, D., White, H., and Coote, D., "In-Space Propulsion Systems Roadmap," Tech. Rep. TA02, National Aeronautics and Space Administration, NASA Headquarters, Washington, D.C., 2012.

${ }^{8}$ Jacobson, D. T., John, J., Kamhawi, H., Manzella, D. H., and Peterson, P. Y., "An Overview of Hall Thruster Development at NASA's John H. Glenn Research Center," 41st Joint Propulsion Conference, Vol. 4242, Tuscon, AZ, July 2005.

${ }^{9}$ Brown, D. L., Beal, B. E., and Haas, J. M., "Air Force Research Laboratory High Power Electric Propulsion Technology Development," 2010 IEEE Aerospace Conference, Big Sky, MT, March 2010.

${ }^{10}$ Liang, R., The Combination of Two Concentric Discharge Channels into a Nested Hall-Effect Thruster, Ph.D. thesis, University of Michigan, Ann Arbor, MI, 2013.

${ }^{11}$ Liang, R. and Gallimore, A. D., "Far-Field Plume Measurements of a Nested-Channel Hall-Effect Thruster," 49th AIAA Aerospace Sciences Meeting, American Institute of Aeronautics and Astronautics, Orlando, FL, Jan. 2011.

${ }^{12}$ Florenz, R. E., The X3 100-kW Class Nested-Channel Hall Thruster: Motivation, Implementation, and Initial Performance, Ph.D. thesis, University of Michigan, Ann Arbor, MI, 2013.

${ }^{13}$ Florenz, R. E., Hall, S. J., Gallimore, A. D., Kamhawi, H., Griffiths, C. M., Brown, D. L., Hofer, R. R., and Polk, J. E., "First Firing of a 100-kW Nested-channel Hall Thruster," 33rd International Electric Propulsion Conference, Washington D.C., Oct. 2013.

${ }^{14}$ Florenz, R. E., Gallimore, A. D., and Peterson, P., "Developmental Status of a 100-kW Class Laboratory Nested Channel Hall Thruster," 32nd International Electric Propulsion Conference, Wiesbaden, Germany, Sept. 2011.

${ }^{15}$ Kamhawi, H., Haag, T. W., Jacobson, D. T., and Manzella, D. H., "Performance Evaluation of the NASA-300M $20 \mathrm{~kW}$ Hall Effect Thruster," 47th Joint Propulsion Conference, Vol. 220, San Diego, CA, Aug. 2011, p. 9.

${ }^{16}$ Soulas, G., Haag, T., Herman, D., and Huang, W., "Performance Test Results of the NASA-457M v2 Hall Thruster," 48th Joint Propulsion Conference, American Institute of Aeronautics and Astronautics, Atlanta, GA, 2012.

${ }^{17}$ Goebel, D. M. and Chu, E., "High-Current Lanthanum Hexaboride Hollow Cathode for High-Power Hall Thrusters," Journal of Propulsion and Power, Vol. 30, No. 1, 2014, pp. 35-40.

${ }^{18}$ Goebel, D. M., Watkins, R. M., and Jameson, K. K., "LaB6 Hollow Cathodes for Ion and Hall Thrusters," Journal of Propulsion and Power, Vol. 23, No. 3, 2007, pp. 552-558.

${ }^{19} \mathrm{Chu}$, E., Goebel, D. M., and Wirz, R. E., "Reduction of Energetic Ion Production in Hollow Cathodes by External Gas Injection," Journal of Propulsion and Power, Vol. 29, No. 5, 2013, pp. 1155-1163.

${ }^{20}$ Kamhawi, H. and VanNoord, J., "Development and Testing of High Current Hollow Cathodes for High Power Hall Thrusters," 48th Joint Propulsion Conference, Vol. 4080, AIAA, Atlanta, GA, 2012.

${ }^{21}$ Thomas, R. E., Kamhawi, H., and Williams, Jr., G. J., "High Current Hollow Cathode Plasma Plume Measurements," 33rd International Electric Propulsion Conference, Washington D.C., Oct. 2013.

${ }^{22}$ Manzella, D., Scaling Hall Thrusters to High Power, Ph.D. thesis, Stanford University, Stanford, CA, 2005.

${ }^{23}$ Brown, D. L., Investigation of Low Discharge Voltage Hall Thruster Characteristics and Evaluation of Loss Mechanisms, Ph.D. thesis, University of Michigan, Ann Arbor, MI, 2009.

${ }^{24}$ Reid, B. M., The Influence of Neutral Flow Rate in the Operation of Hall Thrusters, Ph.D. thesis, University of Michigan, Ann Arbor, MI, 2009.

${ }^{25}$ Walker, M. L. R. and Gallimore, A. D., "Neutral Density Map of Hall Thruster Plume Expansion in a Vacuum Chamber," Review of Scientific Instruments, Vol. 76, No. 5, 2005.

${ }^{26}$ McDonald, M. S., Sekerak, M. J., Gallimore, A. D., and Hofer, R. R., "Plasma Oscillation Effects on Nested Hall Thruster Operation and Stability," 2013 IEEE Aerospace Conference, IEEE, Big Sky, MT, 2013, p. 112.

${ }^{27}$ Hofer, R. R., Goebel, D. M., Snyder, J. S., and Sandler, I., "BPT-4000 Hall Thruster Extended Power Throttling Range Characterization for NASA Science Missions," 31st International Electric Propulsion Conference, Ann Arbor, MI, 2009.

${ }^{28}$ Liang, R. and Gallimore, A. D., "Constant-Power Performance and Plume Measurements of a Nested-Channel Hall-Effect Thruster," 32nd International Electric Propulsion Conference, Wiesbaden, Germany, Sept. 2011.

${ }^{29}$ Jorns, B. A. and Hofer, R. R., "Low Frequency Plasma Oscillations in a 6-kW Magnetically Shielded Hall Thruster," 49th Joint Propulsion Conference, AIAA, San Jose, CA, 2013.

Distribution A: Approved for public release; distribution unlimited. 15 of 15 